\title{
Başarıyla Tedavi Edilen 2 Strangüle Rektal Prolapsus Olgusu Eşliğinde Uygun Cerrahi Yaklaşımın Gözden Geçirilmesi
}

\author{
Review of the Appropriate Surgical Approach with 2 Successfully Treated \\ Strangulated Rectal Prolapse Cases \\ Murat $\mathrm{AKICl}^{1}$ \\ 'Afyonkarahisar Devlet Hastanesi, Genel Cerrahi Kliniği, Afyonkarahisar \\ Geliş Tarihi / Received: 13.05.2014 \\ Kabul Tarihi / Accepted: 12.06.2014
}

\begin{abstract}
ÖZET
Rektal prolapsus, genç ve yetişkinlerin nadir görülen hastalıklarından biridir. Cerrahi tedavide amaç; sigmoid kolonun ve rektumun prolabe olmasının engellenerek onarılması, rektumun boşalmasını bozmadan ve konstipasyon gelişimine neden olmadan kontinansın sağlanmasıdır. Rektumun strangülasyonu, rektal prolapsusun nadir görülen ciddi bir komplikasyonudur. Burada sırasıyla perineal rektosigmoidektomi ve laparoskopik mesh rektopeksi ile başarı ile tedavi edilen iki strangüle rektal prolapsus olgusu sunulmuştur.
\end{abstract}

Anahtar Kelimeler: Rektal prolapsus, komplikasyon, kolorektal cerrahi.

\begin{abstract}
Rektal prolapse, is one of the rare diseases observed in young and adults. The aim of the surgical treatment is to prevent and repair of the prolapse of the sigmoid colon and rectum and to provide continence without disturbing rectal emptying and causing constipation. Strangulation of rectum is a rare and serious complication of rectal prolapse. Herein 2 cases of strangulated rectal prolapse, who were successfully treated with perineal rectosigmoidectomy and laparoscopic mesh rectopexy respectively were reported.
\end{abstract}

Keywords: Rectal prolapse, Complication, Colorectal surgery. 


\section{Giriş̧}

Rektal prolapsus (RP), genç ve yetişkinlerin nadir hastalıklarından biridir. Rektum mukozasının tam kat olarak anüsten dışarıya doğru ters dönerek çıkması ile karekterizedir. RP gelişimiyle ilgili değişik hipotezler ileri sürülmüştür. Bu hipotezler arasında; normalden daha uzun sigmoid koIon, lateral ligaman relaksasyonu ve eşlik eden muskuler atoni, mobil mezorektum ve pelvik taban değişikliklerine bağlı ortaya çıkan pudental sinir hasarı yer almaktadır (1). RP'nin cerrahi tedavisinde amaç; sigmoid kolon ve rektumun prolabe olmasının engellenerek onarılması, rektumun boşalmasını bozmadan ve konstipasyon gelişimine neden olmadan kontinansın sağlanmasıdır (2). RP nedeniyle uygulanacak cerrahi yaklaşım genellikle cerrahın deneyim ve tercihi doğrultusunda, hastanın yaşı, fiziksel durumu, eşlik eden pelvik taban bozuklukları, inkontinans derecesi ve konstipasyon öyküsü göz önünde bulundurularak belirlenir (3).

Rektumun strangülasyonu RP'nin nadir görülen ciddi bir komplikasyonudur. Burada başarı ile tedavi edilen 2 strangüle RP olgusu sunulmuştur ve cerrahi yaklaşım seçenekleri gözden geçirilmiştir.

\section{OLGU SUNUMU}

\section{OLGU 1}

Seksen dört yaşında erkek hasta 30 saat önce makattan dışarı çıkan kitle nedeniyle acil birimine başvurdu. Hikayesinden son 5 yıldır giderek artan şekilde makattan dışarı çıkan ancak kendisi tarafından elle içeri itilebilen kitlesinin bulunduğu öğrenildi. Özgeçmişinde kronik obstruktif akciğer hastalığı ve hipertansiyonu mevcuttu. Perineal muayenede rektumun yaklaşık $10 \mathrm{~cm}$ dışarıya çıktığı, ileri derecede iskemi ve yer yer ülserasyonların olduğu görüldü (Şekil 1). İleri yaş, kronik obstruktif akciğer hastalığı, hipertansiyon gibi komorbiditeleri mevcut olan hastaya perforasyon riski nedeniyle perineal sigmoidektomi uygulandı. Cerrahi sonrası dönemi sorunsuz seyreden hasta 7. günde şifa ile taburcu edildi. Altıncı ayda poliklinik kontrolün-de herhangi bir patoloji saptanmadı.

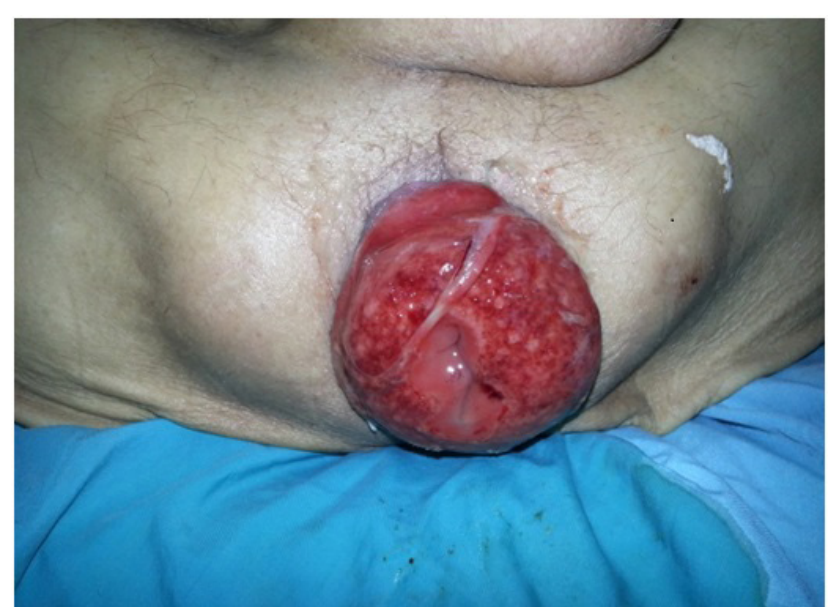

Şekil 1: Olgu 1'e ait prolapse olan rektum dokusu, rektumda iskemik değişiklikler ve yer yer ülserasyonlar.

\section{OLGU 2}

Elli beş yaşında bayan hasta 2 saattir mevcut olan makattan dışarı çıkan kitle nedeniyle başvurdu. Hikayesinden makattan çıkan kitlesinin son 5 yıldır olduğu, giderek arttığı ancak kendisi tarafından elle içeri itilebildiği öğrenildi. Perineal muayenede rektumun yaklaşık $5 \mathrm{~cm}$ dışarıya çıktığı ve hafif iskemik olduğu görüldü. Prolabe alanın içeri atılması sonrası 24. saatte yapılan rektoskopide rektumda iskemi görülmedi. Komorbiditesi olmayan hastaya laparoskopik mesh rektopeksi uygulandı. Cerrahi sonrası dönemi sorunsuz seyreden hasta 3. gün şifa ile taburcu edildi. Altıncı ayda poliklinik kontrolünde herhangi bir patoloji saptanmadı.

\section{TARTIŞMA}

Strangüle RP nadir görülen bir durumdur. Rektum dokusuna kan akışının kısıtlanması ve iskemik değişikliklerin ortaya çıkması ile karekterizedir. Acil cerrahi müdahale gerektirir, ilerleyen olgularda rektumun anterior duvarından perforasyon ve buna bağlı ince barsakların evisserasyonu görülebilir $(4,5)$. Strangüle RP tedavisi için tanımlanmış birçok modalite olmasına rağmen henüz kabul görmüş altın standart bir tedavi yaklaşımı yoktur.

Komplike olmayan RP tedavisinde erken dönemde; defekasyon sırasında ıkınmanın engellenmesi, defekasyon metodu ve zamanının düzenlenmesi, konstipasyonun ortadan kaldırılması, perineal gevşetici egzersizlerin yapılması, elektronik stimülasyon, sklerozan madde 
enjeksiyonu, bant ligasyon ve infrared koagülasyon gibi farklı konservatif yaklaşımların faydalı olabileceği bildirilmesine rağmen, RP hastalarının birçoğunun ek bir cerrahi yönteme intiyaç duyduğu bilinmektedir (6).

Komplike RP tedavisinde ise erken dönemde cerrahi yaklaşım gerekmektedir. Cerrahi tedavide amaç; anatomik bozukluğun düzeltilerek tamirin sağlanması ve defekasyon mekanizmasının mümkün olduğu kadar fizyolojik hale getirilmesidir. Buna yönelik olarak, anal orifisin ve Douglas poşunun daraltılması, pelvik tabanın restore edilmesi, barsak rezeksiyonları, rektumun asılarak sabitlenmesi ya da bunların birkaçının beraber uygulandığı cerrahi yöntemler kullanılmaktadır (7).

RP'nin cerrahi tedavisinde temel olarak abdominal ve perineal olmak üzere 2 yaklaşım mevcuttur. Abdominal yaklaşımlardan en sık uygulananlar; rektopeksi yöntemleri, anterior rezeksiyon, sigmoid rezeksiyon+rektopeksi ve laparoskopik işlemlerdir. Abdominal yaklaşımlar aynı zamanda eşlik eden patolojilerin (sistosel ve uterus prolapsusu) düzeltilmesine olanak tanır ve nüks oranları daha düşüktür. Ancak komplikasyon oranları perineal yaklaşımlara oranla daha yüksektir (7). Buna rağmen hem nüks oranlarının düşük olması, hem de fonksiyonel bozuklukların düzelme şansının daha yüksek oluşu nedeniyle cerrahi açıdan uygun olan düşük riskli hastalarda abdominal yaklaşım önerilmektedir (8). Perineal yaklaşımlar ise nüks oranları yüksek olmasına rağmen komplikasyon oranları daha düşük olduğu için ve cerrahi açıdan yüksek riskli ve uygun olmayan hastalarda tercih edilmektedir. En sık tercih edilen perineal yaklaşımlar; anal Thierch, Delorme ve Altemeier yöntemleridir (7). Abdominal yaklaşım sonrası morbidite oranları \%8-26 arasında iken perineal yöntemlerde ise bu oran \%10'dan daha azdır (9, 10). Cerrahi sonrası nüks oranları karşılaştırıldığında ise abdominal ve perineal yaklaşımlarda bu oran sırasıyla \%0-5 ve \%16 arasında değişmektedir (10).

Burada sunulan stangüle RP'li 2 olgu, perineal ve abdominal yaklaşımla başarıyla tedavi edilmiştir. Birinci olgu, yaşlı ve komorbiditesi yüksek olması nedeniyle acil olarak perineal sig- moidektomi ile tedavi edilmiştir. İkinci olgu ise genç olması, komorbiditesi olmaması, perineal yaklaşımdaki nüks oranlarının daha yüksek olması ve de rektal iskemi süresinin kısa olması nedeniyle rektumun redükte edilmesi sonrası elektif 24. saatte laparoskopik mesh rektopeksi ile tedavi edilmiştir. 6 aylık takipte her 2 olguda da nüks saptanmamıştır.

Sonuç olarak, strangüle rektal prolapsus acil cerrahi tedavi gerektirir. Yaşlı ve komorbiditesi yüksek olan hastalarda perineal yaklaşım en uygun cerrahi yaklaşım seçeneğidir. Ancak rektal iskemi süresi kısa, genç ve komorbiditesi olmayan olgularda rektumun redükte edilmesi sonrası abdominal yaklaşımlar tercih edilmelidir.

\section{KAYNAKLAR}

1. Akcan A, Sözüer $E$, Akyıldız H, et al. Tam kat rektal prolapsus cerrahi tedavisinde rektopeksi ve rektopeksi ile birlikte sigmoid rezeksiyonun karşılaştırılması. Ulusal Cerrahi Dergisi 2007;23(2):54-7.

2. Hoel AT, Skarstein A, Ovrebo KK. Prolapse of the rectum, long-term results of surgical treatment. Int J Colorectal Dis 2009;24(2):201-7.

3. Riansuwan W, Hull TL, Bast J, Hammel JP, Church JM. Comparison of perineal operations with abdominal operations for full-thickness rectal prolapse. World J Surg 2010;34(5):1116-22.

4. Hovey MA, Metcalf AM. Incarcerated rectal prolapserupture and ileal evisceration after failed reduction. Report of a case. Dis Colon Rectum 1997;40(10):1254-7.

5. Papapolychroniadis C, Kaimakis D, Giannoulis K, et al. Spontaneous rupture of the rectosigmoid with small bowel evisceration through the anus. Tech Coloproctol, 2004;8(1):126-32.

6. Corman ML(Editor). Handbook of colon and rectal surgery. 4th Edition. In: Corman ML, Aliıson SI, Kuehne JP. Rectal prolapse. Solitary rectal ulcer, syndrome of the descending penneum and rectocele. Philadelphia: Lippincott Williams \& Wilkins, 2002:246-77.

7. Çalıskan C, Korkut AM, Fırat Ö, Akgün E, Osmanoğlu $H$. Rectal prolapse experience: 68 cases in 27 years. Ege Journal of Medicine 2008;47(1):29-34.

8. Madiba TE, Baig MK, Wexner SD. Surgical Management of rectal prolapse. Arch Surg 2005;140(1):63-73.

9. Kim DS, Tsang CB, Wong WD, et al. Complete rectal prolapse: evolution of management and results. Dis Colon Rectum 1999;42(4):460-9.

10. Gordon $\mathrm{PH}$, Nivatvongs $\mathrm{S}$ (Editors). Principles and practice of surgery for the colon, rectum, and anus. 2nd Edition St. Louis: Quality Medical Publishing Inc, 1999:575-717. 